\title{
Biological parameters predictive of percent dense red blood cell decrease under hydroxyurea
}

\author{
Marie Georgine Rakotoson', Gaetana Di Liberto 1,2, Etienne Audureau ${ }^{3}$, Anoosha Habibi $^{4}$, Christine Fauroux ${ }^{4}$, \\ Sanam Khorgami ${ }^{1,2}$, Anne Hulin ${ }^{5}$, Sylvain Loric ${ }^{6}$, France Noizat-Pirenne ${ }^{1,2}$, Frédéric Galacteros ${ }^{1,4}$ \\ and Pablo Bartolucci ${ }^{1,4^{*}}$
}

\begin{abstract}
Background: Dense red blood cells (DRBCs) are associated with chronic clinical manifestations of sickle-cell-disease (SCD). Hydroxyurea (HU) decreases the percent (\%) DRBCs, thereby improving its therapeutic benefits, especially the prevention of SCD clinical complications, but parameters influencing \%DRBCs remain unknown. The purpose of this study was to determine predictive biological parameters of \%DRBC decline under HU.

Methods: Factors affecting the \%DRBC decrease in SCD patients HU-treated for $\geq 6$ months were analyzed. Biological parameters and the \%DRBCs were determined before starting $\mathrm{HU}$ and after $\geq 6$ months of $\mathrm{HU}$ intake. Bivariate analyses evaluated the impact of each biological parameter variation on \%DRBC changes under treatment. Multivariate analyses assessed the correlations between the decreased \%DRBCs and biological parameters.

Results: The \%DRBCs declined by $40.95 \%$ after $\geq 6$ months on HU. That decrease was associated with less hemolysis, however in several analyses on this group of patients we did not find a statistically significant correlation between decrease in \%DRBCs and increase in $\mathrm{HbF}$. Initial \%DRBC values were the most relevant parameter to predict \%DRBC decline.

Conclusion: Our results strengthen the known HU efficacy in SCD management statistically independently of the classical HbF biological response. Decreasing \%DRBCs is essential to limiting chronic SCD symptoms related to DRBCs and predictive factors might help prevent those manifestations. The results of this study provide new perspectives on indication for HU use, i.e., to prevent SCD-induced organ damage.
\end{abstract}

Keywords: Sickle-cell-disease, Dense red blood cells, Hydroxyurea

\section{Background}

Dense red blood cells (DRBCs) are a subpopulation of RBCs intricately involved in SCD clinical manifestations and are defined as having a density $>1.11 \mathrm{mg} / \mathrm{mL}[1,2]$. They are characterized by a higher mean corpuscular hemoglobin concentration (MCHC) [3-7], because of dehydration caused by $\mathrm{K}^{+}$loss. Dehydration also promotes hemoglobin $\mathrm{S}(\mathrm{HbS})$ polymerization, depending on the $20^{\text {th }}-40^{\text {th }}$ power of the HbS concentration [8]. The percent DRBCs remains stable (no differences for

\footnotetext{
*Correspondence: pablo.bartolucci@aphp.fr

${ }^{1}$ Institut Mondor de Recherche Biomédicale, Unité 955, Equipe 2: Transfusion et Maladies du Globule Rouge, Université Paris-Est Créteil, Créteil, France

${ }^{4}$ Centre de Référence des Syndromes Drépanocytaires Majeurs, Hôpital

Henri-Mondor, APHP, Université Paris-Est Créteil, 51, avenue du

Mal-de-Lattre-de-Tassigny, 94010 Créteil Cedex, France

Full list of author information is available at the end of the article
}

26 patients with $3.2 \pm 1.8$ years of follow-up, $\mathrm{p}=0.79$ ) [9], and is a biological characteristic of homozygous SCD patients at steady state not taking hydroxyurea (HU). DRBCs play an important role in SCD pathophysiology because of their hemorheological properties and their hemolytic propensity. The \%DRBCs is strongly associated with chronic vasculopathy manifestations, e.g., renal dysfunction, leg ulcers, or priapism [9].

HU effectively limits SCD vaso-occlusive crisis, acute chest-syndrome frequencies and mortality. The classical biological parameter of the response to $\mathrm{HU}$ is increased fetal hemoglobin $(\mathrm{HbF})$, a potent anti-HbS-polymerization factor. However, the results of some studies showed that HU can obtain biological benefit independently of increasing $\mathrm{HbF}$, by inhibiting a membrane protein responsible for cell adhesion $[2,10]$. 
Accumulating evidence strengthens the HU indication for chronic vasculopathy, which is associated with the \%DRBCs. We previously showed that HU lowers the \%DRBCs after 6 months, but information is lacking on the biological determinants of a good response, in terms of fewer \%DRBCs, that could support treatment onset for a not yet common indication. Herein, we demonstrate that the strongest predictive factor of HU efficacy is the baseline \%DRBCs itself, underpinning its expected good efficacy in patients at high risk of chronic vasculopathy.

\section{Methods}

\section{Patient characteristics and study design}

This prospective, longitudinal, monocenter study included 56 SCD patients taking HU regularly and followed in our Adult Sickle-Cell-Disease Referral Center. Patients $>18$ years old with SS SCD proven by $\mathrm{Hb}$ electrophoresis were eligible for inclusion. Non-inclusion criteria were pregnancy, blood transfusion during the previous 3 months and refused consent. Patients taking HU were monitored for 6-12 months ( $\geq \mathrm{M} 6)$. The local Institutional Review Board (CPP-Île-de-France IV Saint-Louis Hospital) approved this study. In accordance with the Declaration of Helsinki, all patients gave their signed informed consent; all data were rendered anonymous to protect patients' privacy and confidentiality.

\section{Biological parameter measurements}

Blood was drawn at steady state during outpatient visits. We collected biological parameter values before treatment (day 0, D0) and after $\geq$ M6 on HU. MCHC (g/dL), mean corpuscular $\mathrm{Hb}$ content $(\mathrm{MCH} ; \mathrm{pg}), \mathrm{Hb}(\mathrm{g} / \mathrm{dL})$, mean corpuscular cell volume (MCV; fl), white bloodcell (WBC; G/L), reticulocyte (G/L) and platelet counts (G/L) were determined with a Coulter LH 750 counter (Beckman Coulter, Villepinte, France).

RBC-density curves were obtained with the phthalate density-distribution technique [11]. Serum levels of total bilirubin $(\mu \mathrm{mol} / \mathrm{L})$, lactate dehydrogenase $(\mathrm{LDH} ; \mathrm{IU} / \mathrm{L})$, alanine aminotransferase (ALT; IU/L) and aspartate aminotransferase (AST; IU/L) were assessed with a chemical analyzer (Advia 1650; Siemens Medical Solutions Diagnostics, Holliston, MA, USA).

The $\% \mathrm{HbF}$ was determined by high-pressure liquid chromatography of $\mathrm{Hb}$ using the Variant II Hemoglobin Testing System (Bio-Rad Laboratories, Marnes-la-Coquette, France).

\section{Statistical analyses}

Descriptive results are expressed as means \pm standard deviation (SD) or percentages. Bivariate analyses used the paired $t$-test or Wilcoxon signed-rank test for comparisons of continuous biological parameters between D0 and $\geq$ M6, as appropriate. Pearson correlation coefficients were computed to assess the relationship between \%DRBC decline and collected biological parameters, considering first their D0 to M6 variation and then \%DRBC decline compared to the pretreatment values. Baseline parameters associated with \%DRBC change achieving $\mathrm{p}<0.2$ in unadjusted bivariate analyses were entered into multivariate linear-regression models to identify independent predictors of \%DRBC decrease under HU. The coefficient of determination $\left(\mathrm{r}^{2}\right)$ was used to estimate the percent variability explained by the model. A two-tailed $\mathrm{p}<0.05$ defined significance. All statistical analyses were computed with Stata software v12.1 (StataCorp LP, College Station, TX, USA).

\section{Results}

\section{Patients}

Fifty-six SS patients (24 men and 32 women; mean age $33.7 \pm 9.5$ years) were included in this study. HU was prescribed for the following indications: acute chest syndrome (31), repeated vaso-occlusive crises (21), severe anemia (2), overt stroke (1) or pulmonary hypertension (1). The mean $\mathrm{HU}$ dose was $15 \mathrm{mg} / \mathrm{kg} /$ day taken in a single oral dose.

A larger \%DRBC decrease over the $\geq 6$ months was correlated with aging $(\mathrm{r}=-0.332 ; \mathrm{p}=0.013)$. No significant relationship was found between sex and the \%DRBC change. The \%DRBCs had decreased significantly from $10.5 \pm 8.7 \%$ to $6.2 \pm 4.5 \% \quad(p=0.0003)$. All biological parameter values varied between D0 and after $\geq$ M6 on HU (Table 1 ).

\section{\%DRBC decrease was associated with reduced hemolysis markers but not $\mathrm{HbF}$ variation}

Modifications of monitored biological parameters and \%DRBC change during therapy were analyzed. Bivariate analyses (Table 1) showed that the \%DRBC diminution was positively and significantly correlated with reductions of total bilirubin, AST and LDH ( $\mathrm{p}=0.012,0.020$ and 0.006, respectively). Expressing unadjusted linearregression results as $\beta$-coefficients, declines of one total bilirubin, AST or LDH unit were correlated, respectively, with $0.118,0.113$ or $0.019 \%$ DRBC diminutions. Pertinently, in this group of patients we did not find a statistically significant correlation between decrease in \% DRBCs and increase in $\mathrm{HbF}(\mathrm{r}=-0.080 ; \mathrm{p}=0.556)$ (figure 1 ) or $\mathrm{MCV}$ variation $(\mathrm{r}=-0.059 ; \mathrm{p}=0.665)$ throughout $\mathrm{HU}$ treatment. To reinforce our analysis of $\mathrm{HbF}$ variation according to the \%DRBC decrease, \%DRBC change was tested in each \%HbF-change quartile that comprised 14 patients. Again, no between-group differences were observed according to the \%DRBC decline $(\mathrm{p}=0.32)$.

\section{Baseline parameters predictive of \%DRBC diminution under HU}

Correlations between D0 biological parameters and $\%$ DRBC decline were also evaluated (Table 2). Multivariate 
Table 1 Before and after $\geq$ M6 HU and bivariate analyses of biological parameter variations and \%DRBC change

\begin{tabular}{|c|c|c|c|c|c|}
\hline \multirow[t]{2}{*}{ Parameter } & \multicolumn{3}{|c|}{ Biological parameter values (mean \pm SD) } & \multicolumn{2}{|c|}{ Bivariate analysis } \\
\hline & Before & After $\geq M 6$ & $p$ value & $r$ & $\mathrm{p}$ value \\
\hline$\%$ DRBCs & $10.48 \pm 8.75$ & $6.18 \pm 4.49$ & 0.0003 & & \\
\hline$\% \mathrm{HbF}$ & $7.17 \pm 4.13$ & $17.45 \pm 8.14$ & $<0.0001$ & -0.080 & 0.556 \\
\hline $\mathrm{Hb}(\mathrm{g} / \mathrm{dL})$ & $9.04 \pm 1.28$ & $9.91 \pm 1.67$ & $<0.0001$ & -0.071 & 0.602 \\
\hline WBCs (G/L) & $10.09 \pm 2.54$ & $7.10 \pm 2.03$ & $<0.0001$ & 0.200 & 0.140 \\
\hline MCV (fl) & $89.16 \pm 8.04$ & $108.69 \pm 12.74$ & $<0.0001$ & -0.059 & 0.665 \\
\hline $\mathrm{MCHC}(\mathrm{g} / \mathrm{dL})$ & $33.44 \pm 1.23$ & $33.48 \pm 0.84$ & 0.796 & -0.022 & 0.874 \\
\hline $\mathrm{MCH}(\mathrm{pg})$ & $29.84 \pm 3.23$ & $36.43 \pm 4.64$ & $<0.0001$ & -0.069 & 0.615 \\
\hline Reticulocytes (G/L) & $244.92 \pm 80.84$ & $146.48 \pm 64.99$ & $<0.0001$ & 0.238 & 0.077 \\
\hline Platelets (G/L) & $396.41 \pm 149.51$ & $325.49 \pm 106.09$ & 0.0002 & -0.069 & 0.614 \\
\hline Total bilirubin $(\mu \mathrm{mol} / \mathrm{L})$ & $45.96 \pm 26.76$ & $35.64 \pm 20.48$ & $<0.0001$ & 0.335 & 0.012 \\
\hline ALT (IU/L) & $29.81 \pm 16.22$ & $26.89 \pm 12.14$ & 0.212 & 0.068 & 0.620 \\
\hline AST (IU/L) & $44.04 \pm 17.13$ & $39.67 \pm 16.26$ & 0.149 & 0.311 & 0.020 \\
\hline LDH (IU/L) & $433.02 \pm 180.19$ & $368.98 \pm 139.66$ & 0.0004 & 0.363 & 0.006 \\
\hline
\end{tabular}

Numerical data in bold indicate significant correlation with \%DRBC decrease.

analyses retained the D0 \%DRBCs as the only significant predictor of $\%$ DRBC decline at $\geq 6$ months $(\mathrm{p}<0.0001)$. Patients with high D0 \%DRBCs had the largest \%DRBC decreases (Figure 2). This statistical model explained $76.8 \%$ of the \%DRBC diminution. No correlation was found between \%DRBC reduction and $\mathrm{DO} \mathrm{Hb}, \mathrm{HbF}$ or $\operatorname{MCV}(p=0.501,0.484$ and 0.902 , respectively). Furthermore, $\mathrm{HbF}$ variation under HU was not statistically correlated with $\mathrm{D} 0 \mathrm{HbF}(\mathrm{p}=0.847)$.

\section{Discussion}

This study was undertaken to identify predictors of \%DRBC decrease in a cohort of 56 SS SCD patients taking HU. The \%DRBCs dropped by $40.95 \%$ after $\geq 6$ months on HU. We previously reported a $34 \% \% \mathrm{DRBC}$ decrease [9]. HU diminished SCD patients' DRBC levels, thereby leading

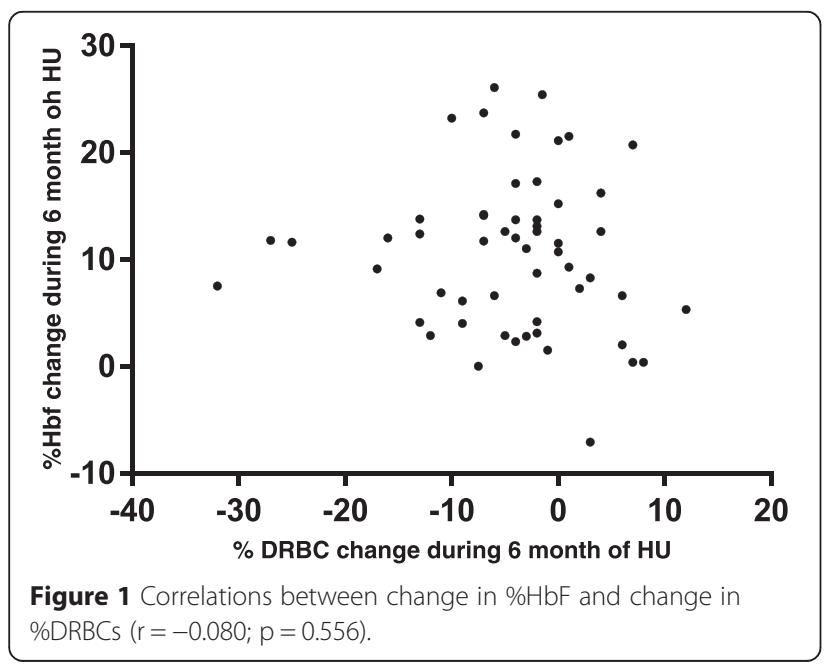

to fewer organ complications and, thus, clinical improvement $[2,5,12,13]$.

Our results demonstrated that the parameter best predicting the \%DRBC diminution was the D0 \%DRBCs itself, with a negative correlation: the higher the D0 \%DRBCs, the greater the \%DRBC decline. This marked \%DRBC decrease further supports HU efficacy on biological and clinical SCD features.

Analyzing the possible relationship between \%DRBC diminution and the evolution of each biological parameter, results showed strong associations between \%DRBC

Table 2 Bivariate and multivariate analyses of D0 biological parameters associated with \%DRBC change under HU

\begin{tabular}{|c|c|c|c|c|}
\hline \multirow[b]{2}{*}{ Parameter } & \multicolumn{2}{|c|}{ Bivariate analysis } & \multicolumn{2}{|c|}{ Multivariate analysis* } \\
\hline & $r$ & $p$ value & $\beta$-coefficient & $p$ value \\
\hline$\% \mathrm{DRBCs}$ & -0.863 & $<0.0001$ & -0.885 & $<0.0001$ \\
\hline WBCs (G/L) & -0.257 & 0.068 & - & - \\
\hline MCV (fl) & -0.018 & 0.902 & - & - \\
\hline $\mathrm{MCHC}(\mathrm{g} / \mathrm{dL})$ & -0.485 & 0.0004 & 0.668 & 0.404 \\
\hline $\mathrm{MCH}(\mathrm{pg})$ & -0.140 & 0.332 & - & - \\
\hline $\mathrm{Hb}(\mathrm{g} / \mathrm{dL})$ & 0.097 & 0.501 & - & - \\
\hline$\% \mathrm{HbF}$ & 0.099 & 0.484 & - & - \\
\hline Reticulocytes (G/L) & -0.437 & 0.002 & -0.004 & 0.703 \\
\hline Platelets (G/L) & 0.200 & 0.159 & - & - \\
\hline Total bilirubin ( $\mu \mathrm{mol} / \mathrm{L})$ & -0.426 & 0.002 & 0.034 & 0.285 \\
\hline ALT (IU/L) & -0.144 & 0.310 & - & - \\
\hline AST (IU/L) & -0.419 & 0.002 & -0.023 & 0.285 \\
\hline LDH (IU/L) & -0.324 & 0.020 & -0.001 & 0.801 \\
\hline
\end{tabular}

*Model also adjusted for age and WBC count: $r^{2}=0.768$. Numerical data in bold indicate significant correlation with \%DRBC decrease. 


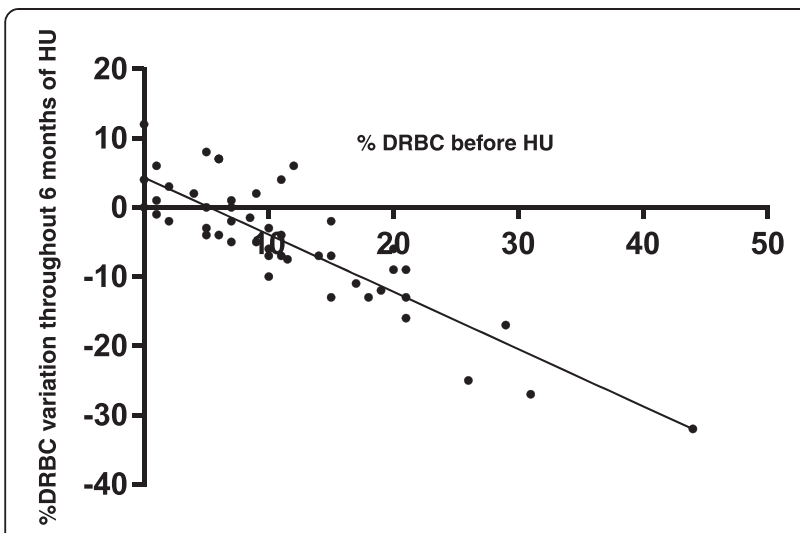

Figure 2 Correlations between \%DRBC variation and D0 \%DRBCs $(r=-0.885, p<0.0001)$.

decline and hemolysis parameters. Total bilirubin, AST and $\mathrm{LDH}$ decreased with \%DRBC, in agreement with previously reported observations that $\mathrm{HU}$ lowers the levels of hemolysis markers [12,14].

While our previous results showed a correlation between \%DRBC and $\mathrm{HbF}$ values in a cohort study on untreated patients [9], in several analyses on this group of patients we did not find a statistically significant correlation between decrease in \% DRBCs and increase in $\mathrm{HbF}$ in terms of therapeutic effects. The lack of correlation between \%DRBC decrease and $\mathrm{HbF}$ increase was confirmed by determining \%DRBC change according to $\mathrm{HbF}$-variation quartiles. Charache et al. studied 32 HU-treated patients [13] and did not find a correlation between $\mathrm{HbF}$ increase and \%DRBC decrease or hemolysis parameters. These striking observations clearly indicate that $\mathrm{HbF}$ is one of the mechanisms but may not be the main pathway through which $\mathrm{HU}$ reduces the \%DRBCs during the course of treatment. Moreover, Goldberg et al. showed that the HbF plateau was reached after 6 months whereas DRBCs were rapidly removed from the circulation according to a biphasic erythrocyte-survival curve [12]. That observation supports the findings that some biological effects of $\mathrm{HU}$ on RBC adhesion [10], ionic transport or MCV [12,15] are faster than $\mathrm{HbF}$ evolution, or could be totally independent, as for endothelial cells [16]. The process underlying the elimination or decrease in \%DRBCs under HU has not yet been completely elucidated. $\mathrm{KCl}$ cotransport, $\mathrm{Na}^{+}$pumps and $\mathrm{Ca}^{2+}$-dependent $\mathrm{K}^{+}$-efflux (Gardos) channels are involved in RBC dehydration and, thus, in DRBC formation [17]. HU has been shown to increase $\operatorname{RBC}[2,12,18]$ and endothelial cell $\mathrm{K}^{+}$contents [16], in part by reducing the $\mathrm{KCl}$-cotransport rate, thereby facilitating $\mathrm{RBC}$ hydration. According to those observations, HU presumably acts, but not exclusively, by raising $\mathrm{HbF}$; however, $\mathrm{HU}$ might also modify $\mathrm{RBC}$-hydration properties involved in SCD pathophysiology.
Notably, we did not find any correlation between the D0 HbF level and its increase, in accordance with a previous study [19].

Because DRBCs and hemolysis are clearly associated with some chronic organ dysfunction that markedly contributes to SCD morbidity and mortality $[9,20]$, prescribing HU early could be an option to prevent those events in patients with very high \%DRBCs, which is one of the best markers of chronic organ involvements. Indeed, authors of recent studies argued for a preventive role of HU in the appearance of organ damage $[21,22]$.

\section{Conclusion}

Our findings confirmed HU efficacy at decreasing the \%DRBCs, which was associated with less hemolysis, and that D0 \%DRBC values were the most relevant parameter predictive of SCD progression. These observations strongly support that, even in the absence of a $\mathrm{HbF}$ response, HU could obtain clinical improvement.

The \%DRBC decrease, a simple and reproducible biological marker of hemolysis and chronic vasculopathy, could serve as a target for treatment management and clinical SCD trials.

The HU mechanism of action on \%DRBC decline remains unclear, since it has only rarely been studied $[9,18]$. To fully understand this unclear point, longitudinal and kinetic analyses of the \%DRBC decrease throughout $\mathrm{HU}$ therapy would be required to complete our results and further investigations are also needed to explain the role of $\mathrm{HU}$ in RBC-rehydration pathways.

\section{Abbreviations}

ALT: Alanine aminotransferase; AST: Aspartate aminotransferase;

DRBCs: Dense red blood cells; Hb: Hemoglobin; HbF: Fetal hemoglobin; HbS: Hemoglobin S; HU: Hydroxyurea; LDH: Lactate dehydrogenase;

MCH: Mean corpuscular Hb content; MCHC: Mean corpuscular hemoglobin concentration; MCV: Mean corpuscular cell volume; RBCs: Red blood cells;

SCD: Sickle-cell-disease; WBCs: White blood cells.

\section{Competing interests}

The authors declare that they have no competing interests.

\section{Authors' contributions}

MGR analyzed data and wrote the paper; GDL supervised and commented on the manuscript; EA performed the statistical analyses; CF and FG collected blood samples and provided patients' clinical data; AH, SK, AH, SL and FNP commented on the manuscript; and PB supervised the project, designed and participated in the research, and wrote the paper. All authors read and approved the final manuscript.

\section{Acknowledgments}

We thank Jugurtha Berkenou for patient monitoring and data collection; Christian Godart and Jean Riu for red cell-density determinations; Janet Jacobson for helpful feedback, discussions and editorial assistance; all the patients who participated in this study; Pierre Fabre Foundation for the grant to fund MGR; and the Pharmacy Department of the Medical School of Antananarivo Madagascar.

\section{Author details}

${ }^{1}$ Institut Mondor de Recherche Biomédicale, Unité 955, Equipe 2: Transfusion et Maladies du Globule Rouge, Université Paris-Est Créteil, Créteil, France. ${ }^{2}$ Etablissement Français du Sang, Île-de-France Mondor, Créteil, France. 
${ }^{3}$ Service de Santé Publique, Hôpital Henri-Mondor, APHP, LIC EA4393, Université Paris-Est Créteil, Créteil, France. ${ }^{4}$ Centre de Référence des Syndromes Drépanocytaires Majeurs, Hôpital Henri-Mondor, APHP, Université Paris-Est Créteil, 51, avenue du Mal-de-Lattre-de-Tassigny, 94010 Créteil Cedex, France. ${ }^{5}$ Laboratoire de Pharmacologie, APHP, Hôpital Henri-Mondor Université Paris Est-Créteil, Créteil, France. ${ }^{6}$ Laboratoire de Biochimie et Génétique, Hôpital Henri-Mondor, Créteil, France.

Received: 18 September 2014 Accepted: 20 April 2015

Published online: 09 May 2015

\section{References}

1. Horiuchi K, Stephens MJ, Adachi K, Asakura T, Schwartz E, Ohene-Frempong K. Image analysis studies of the degree of irreversible deformation of sickle cells in relation to cell density and $\mathrm{Hb} F$ level. Br J Haematol. 1993:85:356-64.

2. Bridges KR, Barabino GD, Brugnara C, Cho MR, Christoph GW, Dover G, et al. A multiparameter analysis of sickle erythrocytes in patients undergoing hydroxyurea therapy. Blood. 1996;88:4701-10.

3. Kaul DK, Fabry ME, Windisch P, Baez S, Nagel RL. Erythrocytes in sickle cell anemia are heterogeneous in their rheological and hemodynamic characteristics. J Clin Invest. 1983;72:22-31.

4. Charache S, Dover GJ, Moyer MA, Moore JW. Hydroxyurea-induced augmentation of fetal hemoglobin production in patients with sickle cell anemia. Blood. 1987;69:109-16

5. Rodgers GP, Dover GJ, Noguchi CT, Schechter AN, Nienhuis AW. Hematologic responses of patients with sickle cell disease to treatment with hydroxyurea. N Engl J Med. 1990;322:1037-45.

6. Schwartz RS, Musto S, Fabry ME, Nagel RL. Two distinct pathways mediate the formation of intermediate density cells and hyperdense cells from normal density sickle red blood cells. Blood. 1998;92:4844-55.

7. Zen Q, Batchvarova M, Twyman CA, Eyler CE, Qiu H, De Castro LM, et al. B-CAM/LU expression and the role of B-CAM/LU activation in binding of low- and high-density red cells to laminin in sickle cell disease. Am J Hematol. 2004;75:63-72.

8. Eaton WA, Hofrichter J. Sickle cell hemoglobin polymerization. Adv Prot Chem. 1990;40:63-279.

9. Bartolucci P, Brugnara C, Teixeira-Pinto A, Pissard S, Moradkhani K, Jouault $H$, et al. Erythrocyte density in sickle cell syndromes is associated with specific clinical manifestations and hemolysis. Blood. 2012;120:3136-41.

10. Bartolucci P, Chaar V, Picot J, Bachir D, Habibi A, Fauroux C, et al. Decreased sickle red blood cell adhesion to laminin by hydroxyurea is associated with inhibition of Lu/BCAM protein phosphorylation. Blood. 2010;116:2152-59.

11. Danon D, Marikovsky V. Determination of density distribution of red cell population. J Lab Clin Med. 1964;64:668-73.

12. Goldberg MA, Brugnara C, Dover GJ, Schapira L, Charache S, Bunn HF. Treatment of sickle cell anemia with hydroxyurea and erythropoietin. N Engl J Med. 1990;323:366-72.

13. Charache S, Dover GJ, Moore RD, Eckert S, Ballas SK, Koshy M, et al. Hydroxyurea: effects on hemoglobin $\mathrm{F}$ production in patients with sickle cell anemia. Blood. 1992;79:2555-65.

14. Olnes M, Chi A, Haney C, May R, Minniti C, Taylor 6th J, et al. Improvement in hemolysis and pulmonary arterial systolic pressure in adult patients with sickle cell disease during treatment with hydroxyurea. Am J Hematol. 2009;84:530-32.

15. Paule I, Sassi H, Habibi A, Pham KP, Bachir D, Galactéros F, et al. Population pharmacokinetics and pharmacodynamics of hydroxyurea in sickle cell anemia patients, a basis for optimizing the dosing regimen. Orphanet J Rare Dis. 2011;... doi: 10.1186/1750-1172-6-30

16. Adragna NC, Fonseca P, Lauf PK. Hydroxyurea affects cell morphology, cation transport, and red blood cell adhesion in cultured vascular endothelial cells. Blood. 1994;83:553-60.

17. Lew VL, Bookchin R. Osmotic effects of protein polymerization: analysis of volume changes in sickle cell anemia red cells following deoxy-hemoglobin S polymerization. J Membr Biol. 1991;122:55-67.

18. Ballas SK, Dover GJ, Charache S. Effect of hydroxyurea on the rheological properties of sickle erythrocytes in vivo. Am J Hematol. 1989;32:104-11.

19. Steinberg MH, Lu ZH, Barton FB, Terrin ML, Charache S, Dover GJ. Fetal hemoglobin in sickle cell anemia: determinants of response to hydroxyurea. Blood. 1997;89:1078-88.
20. Mehari A, Gladwin MT, Tian X, Machado RF, Kato GJ. Mortality in adults with sickle cell disease and pulmonary hypertension. JAMA. 2012;307:1254-6.

21. Thornburg CD, Dixon N, Burgett S, Mortier NA, Schultz WH, Zimmerman SA, et al. A pilot study of hydroxyurea to prevent chronic organ damage in young children with sickle cell anemia. Pediatr Blood Cancer. 2009;52:609-15.

22. Voskaridou E, Chritoulas D, Bilalis A, Plata E, Varvagiannis K, Stamatopoulos G, et al. The effect of prolonged administration of hydroxyurea on morbidity and mortality in adult patients with sickle cell syndromes: results of a 17-year, single-center trial (LaSHS). Blood. 2010;115:2354-63.

\section{Submit your next manuscript to BioMed Central and take full advantage of:}

- Convenient online submission

- Thorough peer review

- No space constraints or color figure charges

- Immediate publication on acceptance

- Inclusion in PubMed, CAS, Scopus and Google Scholar

- Research which is freely available for redistribution

Submit your manuscript at www.biomedcentral.com/submit 